\title{
Crystallization and Preliminary X-ray Diffraction Analysis of ScrY, a Specific Bacterial Outer Membrane Porin
}

\author{
Doris Forst ${ }^{1} \uparrow$, Katrin Schülein ${ }^{2}$, Thomas Wacker ${ }^{1}$, Kay Diederichs ${ }^{1}$ \\ Werner Kreutz', Roland Benz ${ }^{2}$ and Wolfram Welte ${ }^{1}$ \\ ${ }^{1}$ Insiitut für Biophysik und Strahlenbiologie \\ Universität Freiburg, Albertstrasse 23, 7800 Freiburg, Germany \\ ${ }^{2}$ Lehrstuhl für Biotechnologie der Universität Würzburg \\ Röntgenring 11,8700 Würzburg, Germany
}

\begin{abstract}
The sucrose-specific outer membrane porin SerY of Salmonella typhimurium was isolated from Escherichia coli K-12 strain KS 26 containing the plasmid pPSO112. The protein was purified to homogeneity by differential extraction of the cell envelope in the presence of the detergents sodium dodecyl sulfate and lauryl (dimethyl)-amine oxide (LDAO). The porin had apparent molecular weights of $58 \mathrm{kDa}$ and $120 \mathrm{kDa}$ for the monomer and for the trimer, respectively, on SDS/PAGE. The purified trimers were crystallized using poly(ethylene glycol) 2000 and the detergents octylglucoside (OG) and hexyl-(dimethyl)-amine oxide (C6DAO). X-ray diffraction of the crystals showed reflections to $2 \cdot 3 \AA$. The space group of the crystals was $R 3$ and the lattice constants of the hexagonal axes were $a=b=112.85 \AA$ and $c=149.9 \AA$. The crystal volume per unit of protein molecular weight was $3.47 \AA^{3} / \mathrm{Da}$.
\end{abstract}

Keywords: porin; sucrose transport; membrane protein; crystallization; $E$. coli

The outer membrane of Gram-negative bacteria acts as a molecular sieve for hydrophilic solutes (Benz, 1988; \& Bauer, 1988). Responsible for these molecular sieving properties are major classes of outer membrane proteins called porins (Benz, 1988; Benz \& Bauer, 1988). Porins form SDS-resistant trimers, which contain three transmembrane channels (Benz \& Bauer, 1988). Porins can be classified as general or as specific according to their action.

General porins show only slight differences in permeability for cations and anions and otherwise sort the solutes mainly according to molecular mass due to their specific exclusion limits. All specific porins studied to date contain binding sites for one class of solutes such as nucleosides, carbohydrates or anions and are inducible upon growth limitations (Benz, 1988). A prominent example of a specific porin is LamB of Escherichia coli and of other enterobactericeae (Benz, 1988). LamB is part of the maltose- and maltodextrin uptake system. LamB on the other hand is a relatively ineffective channel for sucrose.

The investigation of the metabolic pathway of sucrose in enteric bacteria led to the discovery of a

$\dagger$ Author to whom all correspondence should be addressed. single copy plasmid pUR400 in Salmonella typhimurium (Schmid et al., 1982), which confers to its host the ability to utilize sucrose as the sole carbon source (Schmid et al., 1982, 1988). The plasmid encodes components of the phosphoenolpyruvatedependent carbohydrate phosphotransferase system for uptake and phosphorylation of sugars (Dills et al., 1980; Postma \& Lengeler, 1985). Five different genes have been localized on this plasmid. One of them is serY (Schmid et al., 1982, 1988) with a total length of 1515 base-pairs (Hardesty et al., 1991; Schmid et al., 1991). Its gene product of molecular mass $53 \mathrm{kDa}$ is localized in outer membrane (Schmid et al., 1988). In vivo and in vitro experiments have confirmed the idea that ScrY is a porin with a similar function to LamB, i.e. that it contains a binding site for carbohydrates. Although the affinity for the malto-oligosaccharides is somewhat smaller (Benz et al., 1987; Schülein et al., $1991)$.

The gene scrY from pUR400 and from Klebsiella pneumoniae has been sequenced (Hardesty et al., 1991; Schmid et al., 1991). Comparison of the amino acid sequence with that of LamB of $E$. coli showed $21 \%$ conserved amino acids throughout the primary sequence of both proteins with the exception of a 71 amino acid extension at the $\mathrm{N}$ terminus 
of ScrY. It is not likely that this extension has anything to do with the sugar binding to SerY as it is aighly variable between the known SorY sequences of $S$.typhimurium and $K$. pneumoniae (Hardesty et al., 1991; Schmid et al., 1991). So far it is also unknown if the extension has anything to do witl the unusually high single channel conductance of S.rY as compared with LamB and other specific pori is (Benz, 1988; Ben\% et al., 1987; Schülein et al., 1991).

The general diffusion pore from Rhodobacter capsulatus is the first porin and the second integral mer brane protein for which the three-dimensional structure has been solved at high resolution by X-ray crystallography (Deisenhofer \& Michel, 1989; Weiss et al., 1991 $a, b$ ). Similar structures are not known for specific porins, although LamB has also been crystallized by Garavito et al. (1984). An orthorhombic form has been found by Stauffer et al. (199(1) to diffract to $3 \AA(1 \AA=0.1 \mathrm{~nm})$, so that data collection is possible.

For this study $E$. coli KS26 was constructed by bacteriophage $\mathrm{Pl}_{\text {vir }}$ transduction (Miller, 1972). The donor strain was RAM191 [MCR106 $\Delta(o m p C) 178$ zei-198:: Tn10] (Misra \& Benson, 1988), and the recip ent strain was P1L2360 [MC4100 $\Delta$ (lamb) 106 $\left(o m p F^{\prime}-l a c Z^{+}\right)$Hyb I6-13] (Benson \& Decloux, 1985). Transductants were selected on LB-medium containing tetracycline $(12.5 \mu \mathrm{g} / \mathrm{ml})$. The resulting strair KS26 lacked the outer membrane porins Ompl, $\mathrm{OmpC}$ and LamB. It was transformed with the plasmid PSOI12 $\left(\operatorname{scr} \mathrm{R}^{+}, \operatorname{lac} \mathrm{I}^{\mathrm{Q}}, \operatorname{tac} \mathrm{P}, \operatorname{scr} \mathrm{Y}_{\mathrm{P}}\right.$, scr $\mathrm{Y}^{+}, \mathrm{Ap}^{\mathrm{R}}, \mathrm{Spo}^{\mathrm{R}}$ ) (Schmid et al., 1991). The plasmid is a derivative of $\mathrm{pBR} 322$ and contains the gene $s c r \mathrm{Y}$ after its promoter scr $\mathrm{Y}_{\mathrm{P}}$ in tandem with the tac promoter. The plasmid also contains both the $s c r \mathrm{R}$ repressor gene and the $\operatorname{lacI}^{\mathrm{Q}}$ allele. Using this expression vector scr $\mathrm{Y}$ can be expressed at high level by simultaneous induction both with $\mathrm{D}$-fructose (the real inducer of $s c r R$ ) and IPTG†. Since high 'xpression of ScrY is lethal to the cells, they have to be harvested $90 \mathrm{~min}$ after induction.

The bacteria from an overnight preculture of KS26 pPSO112 in LB supplemented with $12.5 \mu \mathrm{g}$ tetracycline $/ \mathrm{ml}$ and $100 \mu \mathrm{g}$ spectinomycin $/ \mathrm{ml}$ were diluted 1:100 into $250 \mathrm{ml}$ of the same medium. After $4 \mathrm{~h}$ of growth the expression of ScrY was induced by the addition of $10^{-3} \mathrm{M}$-IPTG and of $0.2 \% \mathrm{D}$-fructose. After further growth for $1.5 \mathrm{~h}$ the cells were harvested by centrifugation $(10 \mathrm{~min}$, $1000 \mathrm{~g}$ ) and washed with $50 \mathrm{~mm}$-Tris $\mathrm{HCl}(\mathrm{pH} 7 \cdot 2)$. The cells were resuspended in $5 \mathrm{ml}$ of

$\dagger$ Abbreviations used: PEG, poly(ethylene glycol); $O G$, $\beta$-D-octylglucopyranoside, $\mathrm{C} 7 \mathrm{G}$, heptyl- $\beta$-D-

glueopy ranoside; LDAO, lauryl(dimethyl)-amine oxide; C6DAO hexyl(dimethyl)-amine oxide; HT, 1,2,3.

heptane triol; CHAPSO, 3-[(3-Cholamidopropyl)-dimethylicmmonio]-2-hydroxy-propansulfonate; EDTA, ethylendiamine-N, $N, N^{\prime}, N^{\prime}$-tetra-acetic acid; IPTG, isopropy- $\alpha$-D-thiogalactoside; SDS/PAGE, sodium dodecyl sulfate polyacrylamide gel electrophoresis; $V_{M}$, crystal volume per unit of protein molecular weight.

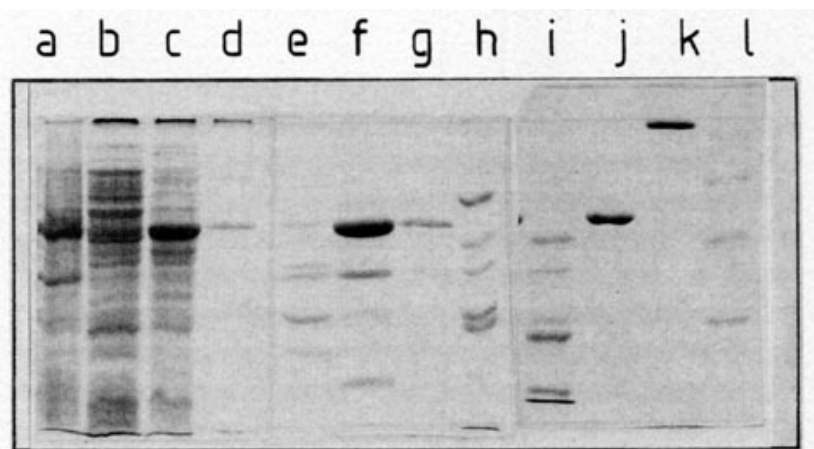

Figure 1. SDS/PAGE (12\%, stained with Coomassie Blue) of the different purification steps of ScrY. Lane a, whole membranes, lane $b$, supernatant of the first wash of the cell envelope fraction with the buffer containing $0.2 \%$ SDS. Lane c, supernatant of the second wash with the same buffer. Lane d, supernatant of the first solubilization step with the buffer containing $2 \%$ Genapol-X 80 . Lane e, supernatant of $0.2 \%$ LDAO, $2 \mathrm{~mm}^{-} \mathrm{MgSO}_{4}$ I,ane $\mathrm{f}$, supernatant of $0.6 \%$ LDAO, $2 \mathrm{mM}^{-\mathrm{MgSO}_{4}}$. A contaminating band of OmpA, migrating at $36 \mathrm{kDa}$ apparent mass is seen. Lane g, supernatant of $0.6 \%$ LDAO, $10 \mathrm{~mm}-\mathrm{MgSO}_{4}$. Lanes $\mathrm{h}$, i, molecular mass markers $(66 \mathrm{kDa}, 45 \mathrm{kDa}, 36 \mathrm{kDa}, 29 \mathrm{kDa}, 24 \mathrm{kDa}$, $20 \mathrm{kDa}$ ). Lane $\mathrm{j}$, eluate from the anion-exchange column. The samples of lanes a to $j$ and lane I were boiled for $10 \mathrm{~min}$. Lane $\mathrm{k}$, as lane $\mathrm{j}$ but without boiling. The protein solution of crystallization thus contains trimers of ScrY. Lane 1, molecular mass markers (205 kda, $116 \mathrm{kda}$, $97 \mathrm{kda}, 66 \mathrm{kDa}, 45 \mathrm{kDa}, 29 \mathrm{kDa})$.

$50 \mathrm{~mm}$-Tris $\cdot \mathrm{HCl}(\mathrm{pH} 7 \cdot 7)$ and passed three times through a French pressure cell at $900 \mathrm{lb} \mathrm{in}^{2}$. Unbroken cells were removed by centrifugation at $1000 \mathrm{~g}$ for $10 \mathrm{~min}$. The supernatant was centrifuged at $100,000 \mathrm{~g}$ for $1 \mathrm{~h}$. The pellet was resuspended in $2 \mathrm{ml}$ of a buffer containing $0.2 \%$ SDS, $10 \mathrm{~mm}$-Tris $\cdot \mathrm{HCl}(\mathrm{pH} \mathrm{7 \cdot 7}), 2 \mathrm{~mm}^{-\mathrm{MgSO}_{4}}$ and centrifuged $(100,000 \mathrm{~g}, \mathrm{l} \mathrm{h})$. This procedure was repeated once. The pellet was resuspended in $2 \mathrm{ml}$ of a buffer containing $2 \%$ of the neutral detergent GenapolX80 (Fluka AG, Neu-Clm, FRG), 10 mm-Tris $\cdot \mathrm{HCl}$ (pH 7-7), $2 \mathrm{~mm}^{-\mathrm{MgSO}_{4}}$ and centrifuged at $100,000 \mathrm{~g}$ for $1 \mathrm{~h}$. The pellet was resolved in $2 \mathrm{ml}$ of a buffer containing $0.2 \%$ of the zwitterionic detergent LDAO (Fluka AG, Neu-Ulm, Germany), $10 \mathrm{~mm}$-Tris $\cdot \mathrm{HCl}, 2 \mathrm{~mm}-\mathrm{MgSO}_{4}(\mathrm{pH} 7 \cdot 7$ ) and centrifuged at $100,000 \mathrm{~g}$ for $\mathrm{l} \mathrm{h}$. The final pellet was solubilized with $2 \mathrm{ml}$ of a buffer containing $0.6 \%$ LDAO, $10 \mathrm{~mm}$-Tris $\cdot \mathrm{HCl}, 2 \mathrm{~mm}-\mathrm{MgSO}_{4} \quad$ (pH 7.7). After centrifugation $(100,000 \mathrm{~g}, 1 \mathrm{~h})$ the supernatant contained about $1 \mathrm{mg}$ SerY/ml (checked with $12 \%$ SDS/PAGE, stained with Coomassie blue; see Fig. 1, lane f). The pellet was dissolved in the same buffer, which contained $0.6 \%$ LDAO, $10 \mathrm{~mm}-\mathrm{MgSO}_{4}$. Another centrifugation led to a supernatant, which contained also SerY (see Fig. 1, lane g).

Protein concentrations were determined with a Coomassie Brilliant Blue staining technique (BioRad Iaboratories GmbH, Munich, Germany).

Prior to crystallization the ScrY-containing 


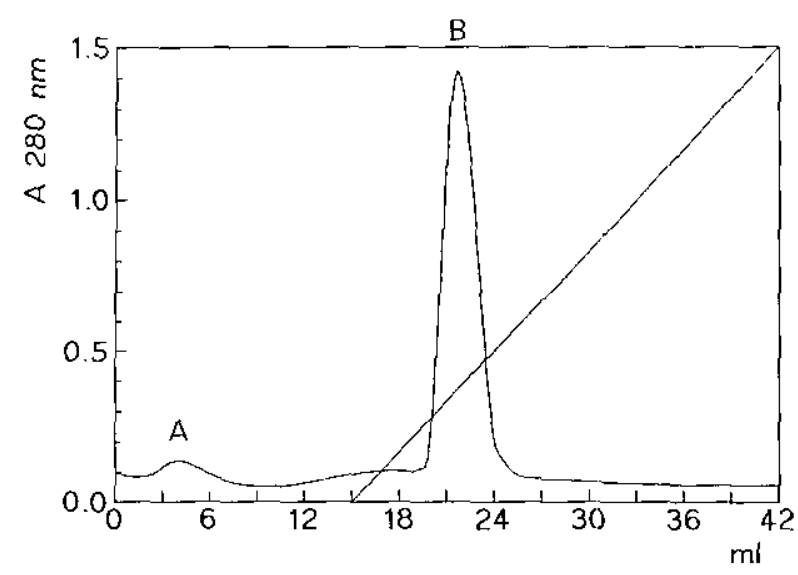

Figure 2. Anion exchange chromatography of SerY. Fractogel END-DEAE was packed into a column with a gel bed volume of $2 \mathrm{ml}$, equilibrated, loaded with the ScrY obtained by IDDAO extraction and washed as described in the text. A linear $\mathrm{LiCl}$ gradient was then applied to the column which eluted the porin as a narrow band at $250 \mathrm{mu}$ (indicated with letter B). Another small peak (indicated as A) contained no protein.

supernatants were subjected to anion exchange chromatography (Fractogel EMD-DEAE obtained from Merck, Darmstadt, FRG). The column was equilibrated with $20 \mathrm{~mm}$-Tris $\cdot \mathbf{H C l}(\mathrm{pH} 8)$,

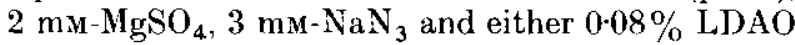
or $1.2 \%(w / v)$ OG. After loading the protein to the column and washing it with $7 \cdot 5$ column volumes of equilibration buffer, the porin was eluted with 13.5 column volumes of a linear 0 м to $1 \mathrm{~m}-\mathrm{LiCl}$ gradient. Fractions containing the eluting protein were concentrated using an ultrafiltration cell (Amicon GmbH, Witten, FRG equipped with YM30 membranes) to a concentration of 8 to $9 \mathrm{mg} / \mathrm{ml}$ and dialyzed against $20 \mathrm{~mm}$-Tris $\cdot \mathrm{HCl}(\mathrm{pH} 8), 20 \mathrm{~mm}$ $\mathrm{MgSO}_{4}, 3 \mathrm{~mm}-\mathrm{NaN}_{3}$, the desired concentration of $\mathrm{LiCl}$ and either $0.08 \%(w / v)$ LDAO or $1.2 \%(w / v)$ $O G$ (denoted in the following as crystallization buffer).

ScrY elutes from the anion exchange column at $0.25 \mathrm{M}-\mathrm{LiCl}$ as a narrow band (see Fig. 2). Without boiling of SorY in sample buffer prior to SDS/PAGE, SerY showed a band at an apparent molecular weight of 120,000 (see Fig. 1, lane k). This converts to a band at 58,000 (see Fig. 1, lane j), when the sample was boiled. Similar results were reported by Schülein et al. (1991).

For crystallization we used the sitting-drop method using the depressions of microtiter plates (PS Mikrotestplatte, oberflächenbehandelt, Greiner und Söhne, GmbH, Nürtingen, Germany). $10 \mu \mathrm{l}$ of the presaturated protein solution were added to one well, the remaining wells were used for the reservoir solution. The cover was sealed with Parafilm. During crystallization the plates were stored at $17^{\circ} \mathrm{C}$.

As precipitants for crystallization we used PEG of various molecular masses as well as ammonium sulfate. For optimization of the crystals a number of different parameters were varied, including $\mathrm{pH}$, detergent for solubilizing ScrY, ionic strength and the type of ions added. We also tried various amphiphilic additives like HT. (Fluka AG, Neu-Ulm, Germany), C6DAO (Oxyl GmbH, Dr. Schlude, Bobingen, Germany) or H7G (Calbiochem GmbH, Frankfurt, Germany).

For $\mathrm{X}$-ray diffraction, the crystals were mounted in glass $1 \mathrm{~mm}$ capillarjes (Müller, Berlin, Germany). Still- and precession photographs were made with a rotating anode $\mathrm{X}$-ray source (Siemens $A Q_{\mathrm{C}}$, Germany) operated at $35 \mathrm{kV}, 20 \mathrm{~mA}$ and equipped with a precession camera (reciprocal lattice explorer, STOE and Cie., Darmstadt, Germany).

With PEG600 and LDAO as detergent, we obtained no crystals. When LDAO was replaced by OG small needle-like crystals were observed.

Using PEG1000 and OG, $100 \mathrm{~mm}-\mathrm{LiCl}$ and $2 \mathrm{mM}^{-} \mathrm{MgSO}_{4}$ were necessary to obtain thin crystalline plates. Precipitation of ScrY occurred at $18 \%$ (w/v) PEGlo00. The optimal presaturation was in the range 12 to $16 \%(\mathrm{w} / \mathrm{v})$, the optimal reservoir concentration range at 20 to $26 \%(\mathrm{w} / \mathrm{v})$. CHAPSO at $1 \%(\mathrm{w} / \mathrm{v}), \mathrm{C} 6 \mathrm{DAO}$ at $3 \%(\mathrm{w} / \mathrm{v})$ and $\mathrm{C} 7 \mathrm{G}$ at $3 \%$ $(w / v)$ all resulted in bigger crystals, which nevertheless were too small for $\mathrm{X}$-ray diffraction experiments. In the presence of C6DAO the crystalline plates grew thicker as under other conditions.

The crystals obtained with PEG2000, OG, $100 \mathrm{~mm}-\mathrm{LiCl}$ and $20 \mathrm{~mm}_{-} \mathrm{MgSO}_{4}$, grew to larger size than those observed with PEG1000 and PEG600. Precipitation of ScrY occurred at $14 \%(\mathrm{w} / \mathrm{v})$ PEG2000. The optimal presaturation was in the range 8 to $10.5 \%(\mathrm{w} / \mathrm{v})$, the optimal reservoir concentration range at $12 \%$ to $15 \%$. Without additives as well as in presence of $\mathrm{C} 7 \mathrm{G}$ they still had the habit of platelets $(400 \mu \mathrm{m} \times 200 \mu \mathrm{m} \times 20 \mu \mathrm{m})$ and diffracted to $7 \AA$. In the presence of $\mathrm{C} 6 \mathrm{DAO}$ they showed an equantic habit and grew within 14 to 21 days to a size of $250 \mu \mathrm{m} \times 200 \mu \mathrm{m} \times 150 \mu \mathrm{m}$. A still photograph of these crystals (see Fig. 3) shows reflections to $2 \cdot 3 \AA$.

Precession photographs allowed us to establish the space group as $R 3$, which can be described by hexagonal axes. The lattice constants are $a=b=112.85 \AA, c=149.9 \AA$.

Assuming the mass of one ScrY molecule $(53,000$, deduced from the amino acid sequence of the mature protein) per asymmetric unit, a $V_{\mathrm{M}}$ value of $3 \cdot 47 \AA^{3}$ dalton can be calculated. This value is close to the $V_{\mathrm{M}}$ reported for the $R 3$ crystals of porin from R. capsulatus of $3.9 \AA^{3}$ /dalton (Nestel et al., 1989) and for the hexagonal crystal form of $0 \mathrm{mpF}$ to $3 \cdot 76 \AA^{3} /$ dalton (Garavito et al., 1983). SerY in the crystal thus should be arranged similarly to porin from $R$. capsulatus (Nestel et al., 1989). Trimers of ScrY should form hexagonal sheets, which are stacked on top of each other to form a cubic closepacked array. The 3 -fold symmetry axis of the space group indicates that ScrY forms trimers in the crystal, as was also concluded from gels and conductivity measurements (Schülein et al., 1991). It is obvious that the band migrating in SDS/PAGE 


\section{References}

Benson, S. A \& Decloux, A. (1985). Isolation and characterization of outer membrane permeability mutants in Eschernchia coli K12. J. Bacteriol 161 . $361-367$.

Benz, R. (1988) Structure and function of porins from gram-negative bacteria. Annu. Rev. Microbiol 42, $359-393$

Benz, R. \& Bauer, K (1988) Permeation of hydrophilic molecules through the outer membrane of gramnegative bacteria. Eur. J Brochem. 176, 1-19

Benz, R.. Schmid, A. \& Vos-Scheperkeuter, G. H (1987) Mechanism of sugar transport through the sugarspecific LamB channel of Eschericha coli outer membrane. $J$. Membrane Biol. 100, 21-29

Deisenhofer, J. \& Michel, H (1989) The photosynthetic reaction centre from the purple bacterium Rhodopseudomonas virudis E.HBO J 8, 2149-2169

bills, S. S., Apperson, A., Schmidt. M. R \& Saier, M. H $\mathrm{Jr}_{\mathrm{r}}$ (1980) (arbohydrate transport in bacteria Microbiol Rev, 44, 385-418.

Figure 3. Still-photograph (exposure time $4 \mathrm{~h}$ ) of a ScrY crystal grown in the presence of $1.2 \%(\mathrm{w} / \mathrm{v}) O(\mathrm{k}$, $100 \mathrm{~mm}-\mathrm{LiCl} .5 \mathrm{~mm}-\mathrm{MgSO}_{4}, \quad 3 \mathrm{~mm}^{-\mathrm{NaN}}, 3 \% \quad(\mathrm{w} / \mathrm{v})$ (6DAC. The PEG2000 concentration in the presaturated and in the reservorr solution were $9 \%(\mathrm{w} / \mathrm{v})$ and $13 \%$ (w/v) respectively. The crystals grew within 3 weeks at $17^{\circ} \mathrm{C}$. The crystal-to-film distance was $75 \mathrm{~mm}$. The bar represents $10 \mathrm{~mm}$ on the film The reflexions extend to $2 \cdot 3 \AA$.

after solubilization without boiling at an apparent molecular mass of 120,000 is the SerY trimer.

Crystals with an equantic habit useful for X-ray diffraction experiments grew in the presence of $3 \%$ $(w / v)$ ('6DAO. This substance seems to act as a "small amphiphile" (Michel, 1983, 1991; Timmins et al., 1991). Interesting, short chain alkanoylamine oxides have also been useful for the crystallization of purple bacterial B800-850 light-harvesting complexes (Welte et al., 1985; Welte \& Wacker, 1991).

For rystallization conditions slightly different from those given above, we observed erystals which grow in space group $P l$ with cell parameters close to those of the $R 3$ crystals $\left(\alpha=90^{\circ}, \beta=90^{\circ}, \gamma=120^{\circ}\right)$. Precession photographs of these crystals show a similar pattern to that of the $R 3$ crystals but with additional reflections with indices that are absent in space group R3. Three-dimensional data sets of these crystals collected on an image-plate detector revealed the absence of a threefold axis along $c$, so that the space group cannot be described as $P 3$. As we consider this space group with nine molecules/ asymmetric unit as unfavorable, we did not try to optimize crystallization conditions. We are currently collecting native and heavy-atom data sets of the ScrY $R 3$ crystals and hope that they and those of LamB (Stauffer et al., 1990) will allow us to determine the structure of substrate-specific porin and of the sugar-binding site inside the channel.

This $w$ rk was supported by the Deutsche Forsehungsgemeinsenaft (SFB60/H4. SFB 176/B9) and the Fonds der Chemischen Industrie.

Garavito, R. MI, Jenkıns, J., Jansonuus, J. N., Karlsson. R. \& Rosenbusch. J P. (1983). X-ray diffraction analysis of matrix porın, an integral membrane protein from Eschericha coli outer membranes. J. Mol. Biol. 164, 313-327

Garavito. R. M., Hinz, L. \& Neuhaus, J. II (1984) The (rystallization of outer membrane proteins from Escherachia coli. J Biol ('hem 259, 4254-4257

Hardesty. C., Ferran, C. \& DiRienzo, J Il (1991). Plasmid-mediated sucrose metabolism in Escherichia coli. characterization of scrY, the structural gene for a phosphoenolpyruvate-dependent sucrose phosphotransferase system outer membrane porin $J$ Bacteriol. 173, 449-456.

Michel, H. (1983) Crystallization of membrane proteins. Trends Biochem sci. 8. 56-59.

Michel, H (1991). General and practical aspects of membrane protein crystallization In Crystallization of Membrane Proteins (M1chel. H, ed.), pp 7388 , ('RC Press, Ine., Boca Raton, C S.A

Miller, J. H. (1972) Experiments in Molecular Genetics, ('old spring Harbor Laboratory Press. Cold Spring Harbor, $\mathrm{NY}$.

Misra. R. \& Benson, S. A. (1988). Isolation and characterization of $\mathrm{OmpC}$ porin mutants with altered pore properties. J. Bacteriol 170, 528-533.

Nestel. ' '. Wacker. T., Woitzlk, D.. Weekesser, J., Kreutz, W \& Welte, W. (1989) Crystallzation and preliminary X-ray analysis of porin from Rhodobacter capsulatus. FEBS Letters, 242, 405-408.

Postma, P W. \& Iengeler, J W (1985). Phosphoenolpyruvate carbohydrate phosphotransferase system of bacteria Mirrobiol. Rev. 49. 232269

Schmid. K, Schupfner. M \& Schmitt R (1982). Plasmid-mediated uptake and metabolism of suerose by Eschernchia coli K 12. J. Bacteriol. 151, 68-76.

Schmid, K., Ebner, R . Altenbuchner, J., Schmitt, R. \& Lengeler, J W (1988) Plasmid mediated sucrose metabolism in Escherichia coli K12 mapping of the scr genes of pUR400. Mol Microbiol. 2, 1-8

Schmid, K, Ebner, R.. Jahreis, K. Lengeler, J W. \& Titgemeyer, F. (1991) A sugar specific porm, ScrY. is involved in sucrose uptake in enteric bacteria $\mathrm{Mol}$ Microbiol 5, 941-950.

Schulein, K.. Schmid. K \& Benz, R. (1991) The sugar specific outer membrane channel SerY contains funetional characteristies of general diffusion pores and 
substrate-specific porins. Mol. Microbiol. 5, 22332241 .

Stauffer, K. A., Page, M. G. P., Hardrneyer, A., Keller, T. A. \& Pauptit, R. A. (1990). Crystallization and preliminary X-ray characterization of maltoporin from E'scherichia coli. J. Mol. Biol. 211, 297-299.

Timmins, P., Hauk, J., Wacker, T. \& Welte, W. (1991). The influence of heptane-1,2,3-triol on the size and shape of LDAO micelles. Implications for the erystallization of membrane proteins. FEBS Letters, 280 , $115-120$.

Weiss, M. S., Kreusch, A., Schiltz, E., Nestel, U., Welte, W., Weckesser, J. \& Schulz, G. (1991a). The structure of porin from Rhodobacter capsulatus at $1.8 \AA$ resolution. FE BS Letters, 280, 379-382.
Weiss, M. S., Abele, U., Weckesser, J., Welte, W., Schiltz, E. \& Schulz, G. $(1991 b)$. Molecular architecture and electrostatic properties of a bacterial porin. Science, $254,1627-1630$.

Welte, W. \& Wacker, T. (1991). Protein-detergent micellar solutions for the crystallization of membrane proteins. In Crystallization of Membrane Proteins (Michel, H., ed.), pp. 107-123, CRC Press, Inc., Boca Raton, U.S.A.

Welte, W., Wacker, T., Leis, M., Kreutz, W., Shiozawa, J., Gad'on, N. \& Drews, G. (1985). Crystallization of the photosynthetic light-harvesting pigment-protein complex B800-850 of Rhodopseudomonas capsulata. FE BS Letters, 182, 260-264. 